\title{
First report on molecular prevalence and identification of Anaplasma platys in dogs in Khon Kaen, Thailand
}

\author{
Biethee Rani Sarker ${ }^{(1)}$, Thongphet Mitpasa1(i), Arayaporn Macotpet² ${ }^{\text {(D) }}$, Pattara-Anong Bupata ${ }^{3}$, \\ Somboon Sangmaneedet ${ }^{1}$ (i) and Weerapol Taweenan ${ }^{1}$ (D)
}

1. Division of Pathobiology, Faculty of Veterinary Medicine, Khon Kaen University, Khon Kaen 40002, Thailand; 2. Division of Medicine, Faculty of Veterinary Medicine, Khon Kaen University, Khon Kaen 40002, Thailand; 3. Veterinary Teaching Hospital, Faculty of Veterinary Medicine, Khon Kaen University, Khon Kaen 40002, Thailand.

Corresponding author: Weerapol Taweenan, e-mail: weerapol@kku.ac.th

Co-authors: BRS: bitheesarker@gmail.com, TM: mitpaxathong96@gmail.com, AM: arayama7972@gmail.com, PB: pattbu@kku.ac.th, SS: sombn_sa@kku.ac.th

Received: 06-05-2021, Accepted: 17-08-2021, Published online: 06-10-2021

doi: www.doi.org/10.14202/vetworld.2021.2613-2619 How to cite this article: Sarker BR, Mitpasa T, Macotpet A, Bupata P, Sangmaneedet S, Taweenan W (2021) First report on molecular prevalence and identification of Anaplasma platys in dogs in Khon Kaen, Thailand, Veterinary World, 14(10): 2613-2619.

\begin{abstract}
Background and Aim: Anaplasma platys is a blood parasite that infects platelets, causing thrombocytopenia. Rhipicephalus sanguineus ticks are believed to transmit $A$. platys. To identify A. platys, nested polymerase chain reaction (PCR) has proven to be an effective diagnostic tool. In this study, the molecular prevalence of $A$. platys infection in dogs was investigated for the $1^{\text {st }}$ time in the Khon Kaen region of Thailand. The association between risk factors and $A$. platys infection was also evaluated.
\end{abstract}

\begin{abstract}
Materials and Methods: A total of 130 blood samples were collected from dogs in Khon Kaen, Thailand. DNA from the samples was extracted and nested PCR was applied for molecular analysis. Platelet count and packed cell volume (PCV) levels were measured. Platelet counts were categorized into four grades: Non-thrombocytopenia (platelets $>200,000$ cells $/ \mu \mathrm{L}$ ), mild thrombocytopenia (platelets $150,000-200,000$ cells $/ \mu \mathrm{L}$ ), moderate thrombocytopenia (platelets 100,000-150,000 cells/ $\mu \mathrm{L}$ ), and severe thrombocytopenia (platelets $<100,000$ cells/ $\mu \mathrm{L}$ ). Four categories for PCV levels of $>37 \%, 30-37 \%, 20-29 \%$, and $<20 \%$ were defined as no anemia, mild anemia, moderate anemia, and severe anemia, respectively. DNA sequencing was analyzed using BTSeq ${ }^{\mathrm{TM}}$ (Barcode-Tagged Sequencing; CELEMICS, Seoul, South Korea) for similarity index.
\end{abstract}

Results: Among the 130 samples, 9 (6.9\%) were positive for A. platys infection. There was an association between low platelet count and infection $(\mathrm{p}<0.05)$. PCV level was also associated with $A$. platys infection $(\mathrm{p}<0.05)$. DNA sequencing results of the nine positive samples showed similarity to known sequences of $A$. platys with $99.36-100 \%$ nucleotide identity. These results suggested low genetic diversity in $A$. platys infecting dogs in the Khon Kaen area.

Conclusion: By amplifying $16 \mathrm{~S} r R N A$, A platys infection was detected in the blood of Thai dogs. Further work should be performed to identify risk factors potentially associated with $A$. platys infection in dogs in Khon Kaen. Other related factors should also be considered, such as location and breeding, as well as the environmental characteristics of each locality. In addition, sampling a larger number of animals may reveal predictors for the positivity of $A$. platys in dogs in this region.

Keywords: Anaplasma platys, molecular prevalence, nested polymerase chain reaction, thrombocytotropic anaplasmosis.

\section{Introduction}

Dog ownership is increasingly common and is known to improve both physical health and mental well-being in owners. However, dog ownership is associated with some potential risks, including the transmission of disease from pets to humans. According to the Bureau of Disease Control and Veterinary Sciences, there are around 8.5 million dogs in Thailand [1]. Different types of parasite can be carried by dogs, which can also present a health risk to humans [2]. Some parasites can be blood-borne, so they can be found in the bloodstream of infected

Copyright: Sarker, et al. Open Access. This article is distributed under the terms of the Creative Commons Attribution 4.0 International License (http://creativecommons.org/licenses/by/4.0/), which permits unrestricted use, distribution, and reproduction in any medium, provided you give appropriate credit to the original author(s) and the source, provide a link to the Creative Commons license, and indicate if changes were made. The Creative Commons Public Domain Dedication waiver (http://creativecommons.org/ publicdomain/zero/1.0/) applies to the data made available in this article, unless otherwise stated. animals. Many blood-borne parasites are spread by insects (vectors). Anaplasma platys is one of the most important parasites and causes major tick-borne disease in dogs of all ages. A. platys infects platelets and is the cause of thrombocytotropic anaplasmosis in canine species. Due to the cyclic nature of this disease, seeing the microorganism inside the platelets of a diseased animal's blood is difficult and may be an incidental finding [3]. Rhipicephalus sanguineus ticks are believed to transmit $A$. platys because the DNA of $A$. platys has frequently been found in these ticks worldwide. South Europe is known as an endemic region for A. platys and there are reports of this infection in Greece [4], Albania [5], Portugal [6], Spain [7], France [8], Romania [9], and Italy [10]. Despite diversity between two Anaplasma spp., commercial ELISA kits are reliable for diagnosing $A$. platys infection serologically because they utilize a cross-reaction of antibodies against Anaplasma phagocytophilum and A. platys [11]. Clinical signs including fever, lethargy, 
anorexia, pale mucous membranes, petechiae, and lymphadenomegaly are commonly seen in $A$. platys infection. For the diagnosis of $A$. platys, polymerase chain reaction (PCR) is commonly used due to its high specificity and sensitivity. Nested PCR is 10 times more sensitive than single PCR. A previous study confirmed the usefulness of nested PCR for assessing the duration of antibiotic treatment required for dogs infected with $A$. platys [12].

To the best of our knowledge, A. platys infection in dogs has not yet been investigated in the Khon Kaen region, Thailand. Nevertheless, Maha Sarakham and Kalasin Provinces (the nearest Thai Provinces to Khon Kaen) have been reported as areas endemic for the tick vector $R$. sanguineus and also for A. platys infection [13].

Against this background, the aims of the current study were to investigate the molecular prevalence of A. platys from blood samples of dogs in Khon Kaen Province and to evaluate the association between risk factors and A. platys infection. This study will help to understand the prevalence of the infection in Khon Kaen and can contribute to improving the control and prevention of $A$. platys infection.

\section{Materials and Methods}

\section{Ethical approval}

The use of animals in the current study was approved under permissions and the guidelines of the Institutional Animal Care and Use Committee of Khon Kaen University (KKU) as permission record no. IACUC-KKU-8/64 and reference no. $660201.2 .11 / 45$ (22).

\section{Study period, area, and population}

During May-November 2020, blood samples were collected from dogs visiting private animal clinics in Mueang district and KKU Veterinary Teaching Hospital, Khon Kaen, Thailand (Figure-1). This was a cross-sectional study. A total of 130 blood samples were collected from the cephalic vein or saphenous vein of domestic dogs. The sample size calculation was based on the reported prevalence of A. platys in domestic dogs in Thailand of $29.4 \%$ [14], with $10 \%$ error allowable. The samples were collected randomly from dogs coming to the KKU Veterinary Teaching Hospital and private animal clinics with the owners' consent. There was no age or sex limitation for inclusion in this study. Blood samples were collected in blood collecting tubes with EDTA, stored in an icebox, and finally brought to the Faculty of Veterinary Medicine, KKU. Each blood sample was divided into two aliquots for hematological and molecular detection. The hematological analysis evaluated the platelet count and packed cell volume (PCV).

\section{Evaluation of platelet count}

An aliquot of a $0.5 \mathrm{~mL}$ blood sample was sent to the Vet Central Lab, Khon Kaen, for hematological analysis. Platelet counts were categorized into

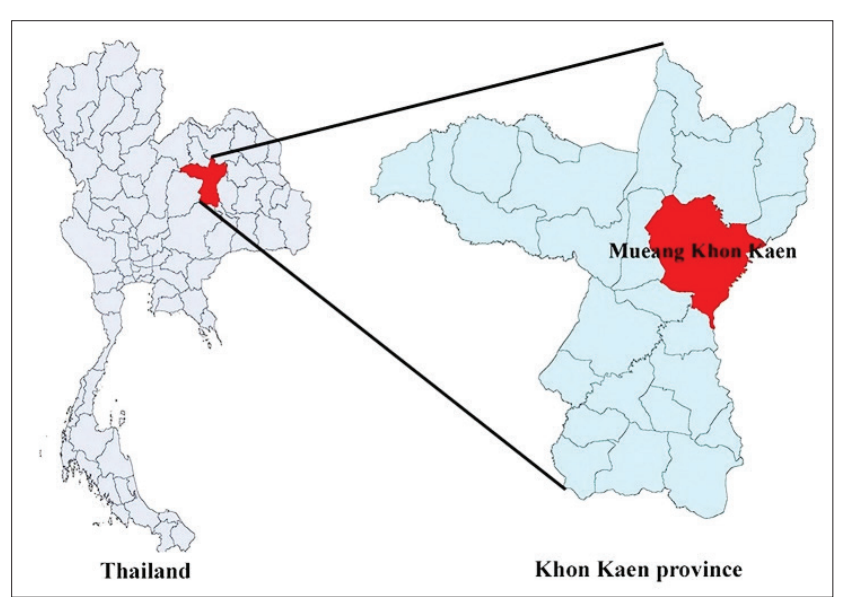

Figure-1: Location of the study area (Source: https://doi. org/10.1186/s12889-018-5871-1).

four grades: severe thrombocytopenia (platelets $<100,000$ cells $/ \mu \mathrm{L}$ ), moderate thrombocytopenia (platelets $100,000-150,000$ cells $/ \mu \mathrm{L}$ ), mild thrombocytopenia (platelets $150,000-200,000$ cells $/ \mu \mathrm{L}$ ), and non-thrombocytopenia (platelets $>200,000$ cells $/ \mu \mathrm{L}$ ) [14].

\section{Evaluation of PCV level of blood}

The PCV level of blood was also measured to understand the relationship between anemia and A. platys infection. First, two-thirds of a heparinized microhematocrit tube or capillary tube was filled with blood. Then, the tube was placed into a calibrated microhematocrit centrifuge machine. After that, the height of the red cell layer was measured by a hematocrit reader. For interpretation of the PCV of blood, the four categories $>37 \%, 30-37 \%, 20-29 \%$, and $<20 \%$ were classified as no anemia, mild anemia, moderate anemia, and severe anemia, respectively [14]. These PCV and platelet counts were measured at the Vet Central Lab, Khon Kaen, Thailand.

\section{DNA extraction}

DNA was extracted from $200 \mu \mathrm{L}$ of each anticoagulated blood sample using a GF-1 blood DNA extraction kit (Vivantis, Malaysia), in accordance with the manufacturer's instructions.

\section{Nested PCR assay}

The 16s rRNA gene of A. platys was amplified by nested PCR using universal primers for Rickettsia (ECC and ECB) and A. platys-specific primers (PLATYS and GA1UR) in the first and second steps, respectively [13] (Table-1).

The PCR reaction consisted of approximately $50 \mathrm{ng}$ of extracted DNA, 10 pmol each primer, $200 \mu \mathrm{M}$ each dNTP, $1.5 \mathrm{mM} \mathrm{MgCl}_{2}$, and 1 unit Taq polymerase (Vivantis). PCR conditions were initial denaturation at $95^{\circ} \mathrm{C}$ for $2 \mathrm{~min} ; 35$ cycles of denaturation at $95^{\circ} \mathrm{C}$ for $1 \mathrm{~min}$, annealing at $60^{\circ} \mathrm{C}$ and $62^{\circ} \mathrm{C}$ for the $1^{\text {st }}$ and $2^{\text {nd }}$ steps for $1 \mathrm{~min}$, and extension at $72^{\circ} \mathrm{C}$ for $2 \mathrm{~min}$; and then final extension at $72^{\circ} \mathrm{C}$ for 5 min in a Biometra GmbH Thermocycler (Germany). After that, PCR products were identified in 1\% agarose gels and visualized under ultraviolet light [13]. 
Table-1: Universal Rickettsia and Anaplasma platys-specific primers and corresponding product size.

\begin{tabular}{lll}
\hline Primer & Sequence & Product size (bp) \\
\hline ECC (F) & 5'AGA-ACG-AAC-GCT-GGC-GGC-AAG-CC 3' \\
ECB (R) & 5' CGT-ATT-ACC-GCG-GCT-GCT-GGC-A 3' \\
PLATYS (F) GA1UR (R) & 5' TTT-GTC-GTA-GCT-TGC-TAT-G 3' \\
& 5' GAG-TTT-GCC-GGG-ACT-TCT-TCT 3' \\
\hline
\end{tabular}

\section{DNA sequencing and analysis of obtained sequences}

After purification with a gel purification kit (Vivantis), all positive samples were sent for sequencing using BTSeq ${ }^{\mathrm{TM}}$ (Barcode-Tagged Sequencing; CELEMICS, Seoul, South Korea). The sequences were compared to other $A$. platys reference sequences in GenBank using BLAST search. MEGA X software (Molecular Evolutionary Genetics Analysis software available at https://www.megasoftware.net/) was used to align samples with the GenBank database for confirmation of the status as $A$. platys and to construct a phylogenetic tree based on the neighbor-joining method with 500 replicates for bootstrap analysis.

\section{Statistical analysis}

Risk factors, including PCV and platelet count were evaluated for the association with the molecular prevalence using a logistic regression test in the IBM SPSS Statistics program, Version 17 (IBM, NY, USA). The prevalence ( $\%)$, p-value, and 95\% confidence interval were calculated. $\mathrm{p}<0.05$ was considered statistically significant.

\section{Results}

A total of 130 blood samples from dogs were collected randomly from seven different private animal clinics and KKU Veterinary Teaching Hospital, Khon Kaen, Thailand. Among these 130 samples, 9 (6.9\%) were found to be positive by PCR. Of these nine positive samples, eight were from the KKU Veterinary Teaching Hospital and one from a private clinic. All nine samples showed positivity with a clear band size (402 bp) (Figure-2).

The associations between the prevalence of $A$. platys infection and risk factors including rearing status and tick infestation were evaluated. The results showed that nine samples were found positive for $A$. platys. According to the tick infestation factor, the prevalence of the dogs with the presence of tick was $11.8 \%(8 / 68)$, whereas the prevalence of the dogs with no tick found was $1.6 \%$ (1/62) (Table-2). Moreover, the infection rates in dogs confined to the house, allowed into the yard, and free-roaming were $5.9 \%(1 / 17), 4.2 \%(3 / 72)$, and $12.2 \%$ (5/41), respectively (Table-2). The results showed that rearing status and tick infestation were not individual factors significantly associated with $A$. platys infection, but in combination, an association between tick infestation and infection was identified (Table-2).

\section{Measurement of platelet count and PCV value}

According to platelet counts, the prevalence in dogs with severe thrombocytopenia, moderate

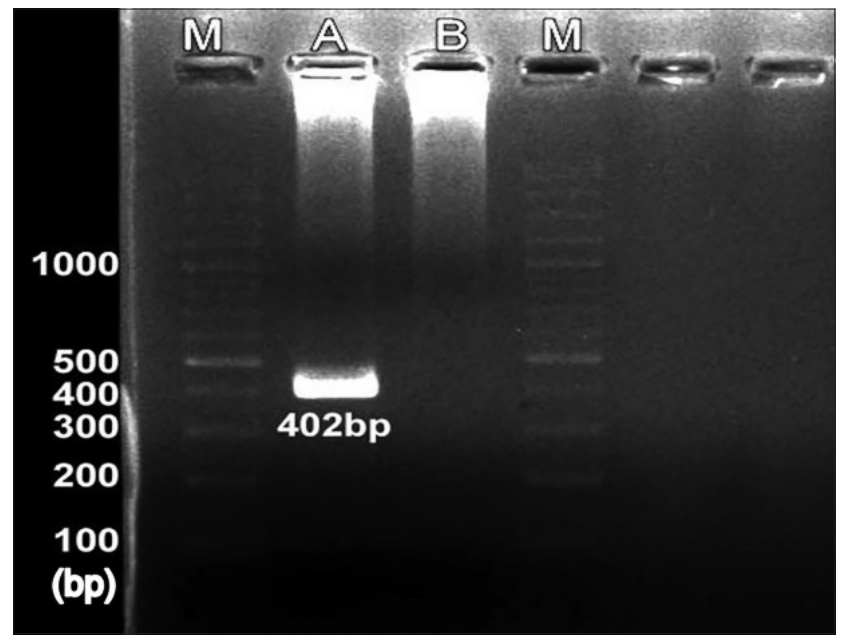

Figure-2: After gel electrophoresis, samples show the positive band with $402 \mathrm{bp}$. Lane M: Ladder, lane A: Positive sample, lane B: Negative control.

thrombocytopenia, mild thrombocytopenia, and non-thrombocytopenia group was $15.8 \%$ (3/19), $26.7 \%(4 / 15), 7.7 \%(1 / 13)$, and $1.2 \%(1 / 83)$, respectively (Table-3). Most of the dogs (83/130; 63.8\%) were in the non-thrombocytopenia group. Platelet count was significantly associated with $A$. platys infection in this study $(\mathrm{p}=0.04$, Table-3). The table shows that the moderate thrombocytopenia group was most commonly observed in infected dogs $(26.7 \%$; 4/15) (Table-3).

The PCV values were categorized into four levels. $\mathrm{PCV}<20 \%, 20-29 \%, 30-37 \%$, and $>37 \%$ were categorized as severe anemia, moderate anemia, mild anemia and no anemia, respectively. The results indicate that the prevalence of $A$. platys infection in dogs with severe anemia, moderate anemia, mild anemia, and no anemia was $28.6 \%$ (4/14), 18.2\% (2/11), 11.1 (2/18), and 1.1 (1/87), respectively (Table-3). Most of the dogs $(87 / 130 ; 67 \%)$ were in the no anemia group. The severe anemia group was associated with a higher risk of infection than the mild, moderate, and no anemia groups. The association between PCV level and $A$. platys infection was significant $(\mathrm{p}=0.024)$ in this study. Combined effects of platelet count and PCV level showed no association with $A$. platys infection (Table-3).

\section{Phylogenetic relationship of revealed A. platys-like blood parasite with known strains}

To evaluate phylogenetic relationships, the sequences of $A$. platys variants in this study and those described previously were compared to each other. These nine gene sequences shared 99.36-100\% 
Table-2: Prevalence of Anaplasma platys infection and some related statistical characteristics (risk factors).

\begin{tabular}{|c|c|c|c|c|c|}
\hline \multirow[t]{2}{*}{ Variables } & \multirow{2}{*}{$\begin{array}{c}\text { \% prevalence (no. of } \\
\text { positive/no. of samples) }\end{array}$} & \multicolumn{2}{|c|}{ Univariable analysis } & \multicolumn{2}{|c|}{ Multivariable analysis } \\
\hline & & OR (95\% CI) & p-value & Adjusted OR (95\% CI) & p-value \\
\hline \multicolumn{6}{|l|}{ Tick infestation } \\
\hline No tick found & $1.6(1 / 62)$ & 1 & & 1 & \\
\hline Presence of tick & $11.8(8 / 68)$ & $8.13(0.99-67.03)$ & 0.05 & $15.25(1.23-187.84)$ & 0.03 \\
\hline \multicolumn{6}{|l|}{ Rearing status } \\
\hline Around the house & $4.2(3 / 72)$ & 1 & & 1 & \\
\hline Raise in room & $5.9(1 / 17)$ & $1.43(0.14-14.74)$ & 0.76 & $0.25(0.02-3.19)$ & 0.29 \\
\hline Independent & $12.2(5 / 41)$ & $3.19(0.72-14.13)$ & 0.13 & $0.56(0.09-3.39)$ & 0.52 \\
\hline
\end{tabular}

Table-3: Factors associated with platelet count and PCV level in reference to Anaplasma platys infection.

\begin{tabular}{|c|c|c|c|c|c|}
\hline \multirow[t]{2}{*}{ Variable } & \multirow{2}{*}{$\begin{array}{c}\% \text { prevalence (no. } \\
\text { of positive/no. of } \\
\text { samples) }\end{array}$} & \multicolumn{2}{|c|}{ Univariable analysis } & \multicolumn{2}{|c|}{ Multivariable analysis } \\
\hline & & OR (95\% CI) & p-value & $\begin{array}{l}\text { Adjusted OR } \\
(95 \% \mathrm{CI})\end{array}$ & p-value \\
\hline Platelet count & & & 0.04 & & 0.46 \\
\hline $\begin{array}{l}\text { Severe thrombocytopenia } \\
<100,000 \mathrm{Cell} / \mu \mathrm{L}\end{array}$ & $15.8(3 / 19)$ & $20.50(1.97-213.42)$ & 0.007 & $3.17(0.05-216.12)$ & 0.59 \\
\hline $\begin{array}{l}\text { Moderate thrombocytopenia } \\
(100,000-150,000) \text { cell } / \mu \mathrm{L}\end{array}$ & $26.7(4 / 15)$ & $21.87(2.28-209.42)$ & 0.012 & $8.74(0.11-683.41)$ & 0.33 \\
\hline $\begin{array}{l}\text { Mild thrombocytopenia } \\
(150,000-200,000) \text { cell } / \mu \mathrm{L}\end{array}$ & $7.7(1 / 13)$ & $6.83(0.4-116.63)$ & 0.184 & $1.74(0.02-123.69)$ & 0.8 \\
\hline $\begin{array}{l}\text { Non-thrombocytopenia } \\
>200,000 \text { cell/ } \mu \mathrm{L}\end{array}$ & $1.2(1 / 83)$ & 1 & & & \\
\hline PCV level & & & 0.024 & & 0.26 \\
\hline Severe anemia $(<20 \%)$ & $28.6(4 / 14)$ & $34.40(3.49-338.70)$ & 0.002 & $16.36(0.26-1020.67)$ & 0.19 \\
\hline Moderate anemia $(20-29 \%)$ & $18.2(2 / 11)$ & $19.11(1.57-232.06)$ & 0.021 & $5.57(0.06-496.39)$ & 0.45 \\
\hline Mild anemia $(30-37 \%)$ & $11.1(2 / 18)$ & $10.75(0.92-125.71)$ & 0.058 & $2.08(0.03-165.05)$ & 0.74 \\
\hline No anemia $(>37 \%)$ & $1.1(1 / 87)$ & 1 & & & \\
\hline
\end{tabular}

nucleotide identity with known sequences of A. platys. For example, PH42 and AH52 shared $100 \%$ nucleotide identity with $A$. platys strain S3 chromosome CP046391. Meanwhile, AH97 showed 99.78\%, and AH119, AH100, and AH128 showed $99.78 \%, 99.76 \%$, and $99.75 \%$ identity to $A$. platys strain S3 chromosome CP046391, respectively. Moreover, AH125 and AH115 showed 99.67\% and $99.36 \%$ similarity to $A$. platys isolate D35 ribosomal RNA KX792089. Alignment of the sequences from the current study and those of reference $A$. platys in GenBank indicated identical nucleotide sequences of $A$. platys (Figure-3). The alignment showed that there were differences in some bases in the outgroups Ehrlichia canis MF153971, Candidatus Anaplasma MN882724, Ehrlichia chaffeensis NR074500, and Rickettsia NR 118679. A. platys MK736884 and sample AH104 also showed differences in the aligned part.

The phylogenetic tree showed that the samples PH42, AH58, AH97, AH100, AH104, AH115, AH119, AH125, and AH128 were closely related to each other and matched with references $A$. platys AY040850, A. platys GQ395383, A. platys AY530806, Ehrlichia platys AF286699, A. platys MN075279, and A. platys MK736884 (Figure-4). According to the phylogenetic tree, the outgroups E. canis MF153971 and Candidatus Anaplasma MN882724 showed similarity with $A$. platys sequences, but $E$. chaffeensis
NR074500, A. phagocytophilum MW715066, and Rickettsia NR 118679 did not.

\section{Discussion}

This study molecularly investigated the prevalence of $A$. platys infection in dogs in Khon Kaen Province, Thailand. Samples from KKU Veterinary Teaching Hospital covered dogs from a large area of Khon Kaen, whereas private clinics covered smaller populations. In this study, $6.9 \%$ of the PCR results were positive, which is a different rate of $A$. platys infection as identified by PCR evaluation in other provinces of Thailand. Previously, A. platys infections were reported in multiple studies in different provinces in Thailand, for example, Kalasin Province (29.4\%) [14], Maha Sarakham Province (29.2\%) [13], and Buriram Province (30.61\%) [15], but at different rates from the current study.

However, the prevalence in the present study is similar to a result reported in Songkhla (4.4\%), where samples were collected from stray dogs [16], although the present study samples were collected only from hospitalized dogs. Location and climate are factors potentially influencing this variation of results. In Brazil, a study revealed a high prevalence of $A$. platys infection of $32.9 \%$ [17]. Climatic variation, the dog rearing system, and the prevalence of ticks, among others, may be behind these differences.

An association was found between PCV level and infection $(p=0.024)$, which contrasts with the 


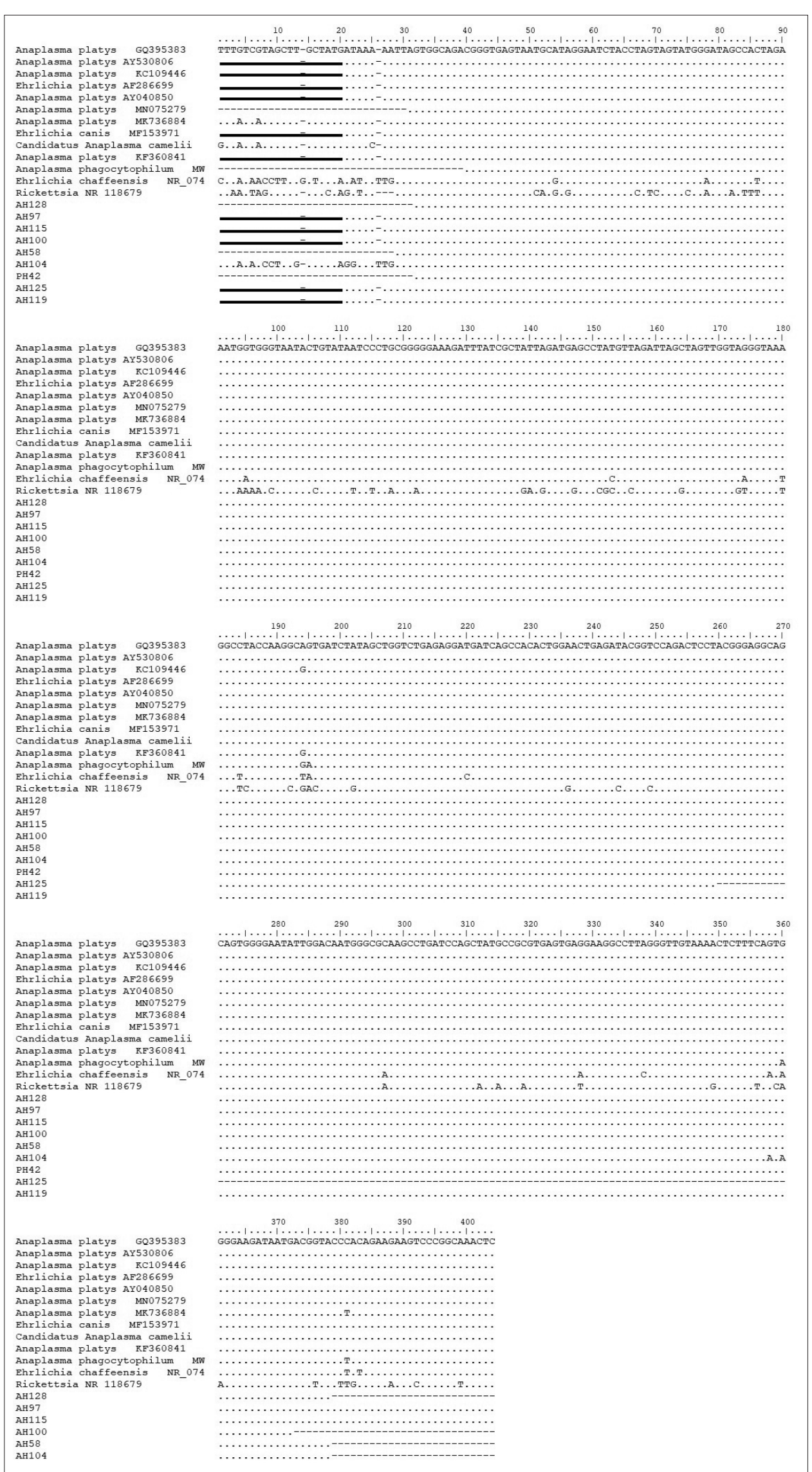

Figure-3: Alignment of the sequences obtained with the $16 S$ rRNA used in our study and those of $A$. platys in GenBank. (..) denotes the identical nucleotide sequence to that of $A$. platys. (--) denotes absence of nucleotides and ( $\_$) denotes primer sequence.

findings in studies from Kalasin ( $\mathrm{p}=0.294)$ and Maha Sarakham Provinces $(\mathrm{p}=0.816)$. Regarding platelet count, a significant association between platelet count and $A$. platys infection was identified $(\mathrm{p}=0.04)$. This 


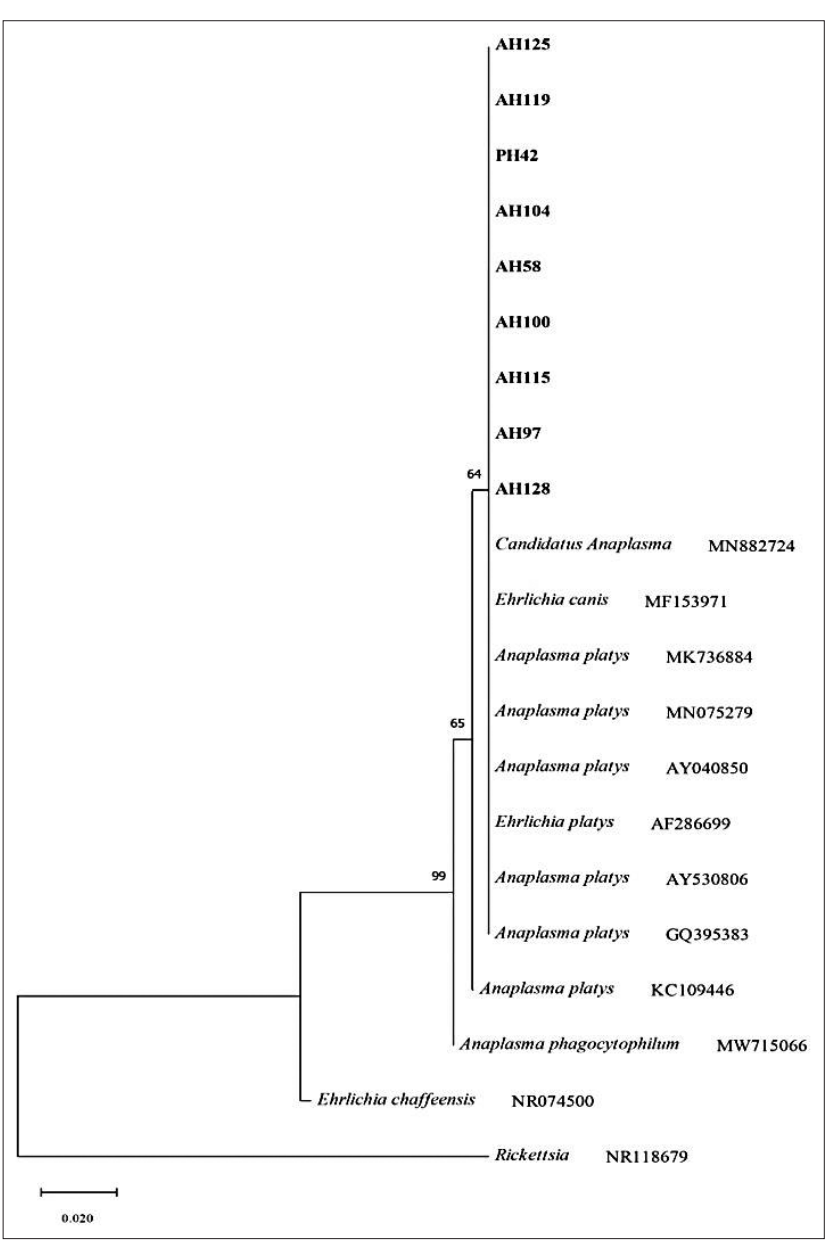

Figure-4: Phylogenetic tree based on 16S RNA gene and drawn using MEGA $X$ software. Trees were obtained by neighbor-joining method. The numbers at the nodes are the proportions of 500 bootstrap with Kimura 2-parameter model. Samples detected in this work were highlighted.

conclusion differs from findings in the previous studies in Thailand at Kalasin $(0.807 \%)$ and Maha Sarakham Provinces. Sample collection strategy could be a factor behind this discrepancy, with the present study only focusing on hospitalized dogs.

The close relationship between $16 \mathrm{~S}$ rDNA of $A$. platys from various regions worldwide agrees with the hypothesis that $A$. platys strains are not separated geographically [18]. Figure-4 displays that the phylogenetic tree was separated into four major clusters and $A$. platys Khon Kaen was within the same cluster. Within these four clusters, little genetic diversity was observed, suggesting slow and homogeneous evolution [19]. In this study, A. platys was also found to be more closely related to E. platys, which supports an earlier study [20].

As suggested in the present work, the few differences in the $16 S r R N A$ gene sequences compared to those available in GenBank might be due to sequencing or PCR error, but may be due to variations in the sequences of strains of the same species as well. Finally, our primers detected A. platys in canine blood, which resulted in new $16 S$ rRNA sequences being obtained from A. platys infections of Thai dogs.
Although the $16 S r R N A$ sequences were highly conserved among geographically diverse strains of these organisms, additional analyses of genes were recommended (e.g., outer membrane protein gene families), which could help elucidate the diversity and evolution of strains from different geographical areas.

\section{Conclusion}

The nested PCR method employed "two-step" direct amplification using an $A$. platys-specific primer set. To increase the sensitivity of the PCR, a nested PCR approach was developed in this study. This study provides epidemiological information about the prevalence of pathogens transmitted by ticks in Khon Kaen Province to establish control and preventive measures against A. platys infection in dogs. Although light microscopy analysis appeared to be a reliable method to diagnose A. platys infection, the use of PCR was more specific to identify this parasite. The results show that these pathogens circulate among canines in the Khon Kaen region of Thailand. The results of a phylogenetic analysis demonstrated very high homology values $(100 \%)$ with a bootstrap value of $100 \%$. This also shows that there is low genetic diversity in A. platys infecting dogs in the Khon Kaen area. The identification of risk factors that may be associated with $A$. platys infection in dogs in Khon Kaen should be further investigated, such as factors related to the location and breeding, as well as the environmental characteristics of each locality. In addition, sampling a larger number of animals may demonstrate the possible risk factors influencing the positivity of dogs for A. platys in this region. The development of molecular techniques appears to facilitate the identification of these diseases, and information on the occurrence of ticks and pathogens transmitted by them will help veterinary services to diagnose diseased animals correctly.

\section{Authors' Contributions}

WT: Conceptualization, funding acquisition, project administration, and reviewed and revised the manuscript. BRS and WT: Data curation. methodology, and visualization. BRS: Formal analysis, software, and drafted the manuscript. TM, BRS, AM, and PB: Investigation. TM, AM, and PB: Resources. SS: Supervision. WT and SS: Validation. All authors read and approved the final manuscript.

\section{Acknowledgments}

The authors are thankful to the Veterinary Teaching Hospital, Khon Kaen University and private animal clinics. This research was funded by the Faculty of Veterinary Medicine, Khon Kaen University, Thailand (Grant no. VMKKU 68/2563).

\section{Competing Interests}

The authors declare that they have no competing interests. 


\section{Publisher's Note}

Veterinary World remains neutral with regard to jurisdictional claims in published map and institutional affiliation.

\section{References}

1. Sattaburuth, A. (2016) Critics Savage 99-year Land Lease Scheme. Bangkok Post, Bangkok.

2. Shaw, S.E., Day, M.J., Birtles, R.J. and Breitschwerdt, E.B. (2001) Tick-borne infectious diseases of dogs. Trends Parasitol., 17(2): 74-80.

3. Ferreira, R.F., de Mello Figueiredo Cerqueira, A., Pereira, A.M., Guimarães C.M., de Sá, A.G. and da Silva Abreu, F. (2007) Anaplasma platys diagnosis in dogs. comparison between morphological and molecular tests. Int. J. Appl. Res. Vet. Med., 5(3): 113.

4. Kontos, V., Papadopoulos, O. and French, T. (1991) Natural and experimental canine infections with a Greek strain of Ehrlichia platys. Vet. Clin. Pathol., 20(4): 101-105.

5. Hamel, D., Shukullari, E., Rapti, D., Silaghi, C., Pfister, K. and Rehbein, S. (2016) Parasites and vector-borne pathogens in client-owned dogs in Albania. Blood pathogens and seroprevalences of parasitic and other infectious agents. Parasit. Res., 115(2): 489-499.

6. Cardoso, L., Tuna, J., Vieira, L., Yisaschar-Mekuzas, Y. and Baneth, G. (2010) Molecular detection of Anaplasma platys and Ehrlichia canis in dogs from the North of Portugal. Vet. J., 183(2): 232-233.

7. René-Martellet, M., Lebert, I., Chêne, J., Massot, R., Leon, M. and Leal, A. (2015) Diagnosis and incidence risk of clinical canine monocytic ehrlichiosis under field conditions in Southern Europe. Parasit. Vectors, 8(1): 1-10.

8. Brouqui, P. (2002) Anaplasma platys (Ehrlichia platys) infection in a dog in France: Description of the case, and characterization of the agent. Revue. Méd. Vét., 153(2): 85-90.

9. Andersson, M., Turcitu, M.A., Stefanache, M., Tamba, P., Barbuceanu, F. and Chitimia, L. (2013) First evidence of Anaplasma platys and Hepatozoon canis co-infection in a dog from Romania-a case report. Ticks Tick Borne Dis., 4(4): 317-319.

10. De la Fuente, J., Torina, A., Naranjo, V., Nicosia, S., Alongi, A. and La Mantia, F. (2006) Molecular characterization of Anaplasma platys strains from dogs in Sicily, Italy.
BMC Vet. Res., 2(1): 1-5.

11. Wong, S.S., Teng, J.L., Poon, R.W., Choi, G.K., Chan, K.H. and Yeung, M.L. (2011) Comparative evaluation of a pointof-care immunochromatographic test SNAP 4Dx with molecular detection tests for vector-borne canine pathogens in Hong Kong. Vector-Borne Zoon Dis., 11(9): 1269-1277.

12. Chang, W.L. and Pan, M.J. (1996) Specific amplification of Ehrlichia platys DNA from blood specimens by two-step PCR. J. Clin. Microbiol., 34(12): 3142-3146.

13. Piratae, S., Sae-chue, B., Sukumolanan, P. and Phosri, A. (2017) Molecular detection of blood pathogens and their impacts on levels of packed cell volume in stray dogs from Thailand. Asian Pac. J. Trop. Dis., 7(4): 233-236.

14. Piratae, S., Senawong, P., Chalermchat, P., Harnarsa, W. and Sae-Chue, B. (2019) Molecular evidence of Ehrlichia canis and Anaplasma platys and the association of infections with hematological responses in naturally infected dogs in Kalasin, Thailand. Vet. World, 12(1): 131.

15. Rucksaken, R., Maneeruttanarungroj, C., Maswanna, T., Sussadee, M. and Kanbutra, P. (2019) Comparison of conventional polymerase chain reaction and routine blood smear for the detection of Babesia canis, Hepatozoon canis, Ehrlichia canis, and Anaplasma platys in Buriram Province, Thailand. Vet. World, 12(5): 700.

16. Liu, M., Ruttayaporn, N., Saechan, V., Jirapattharasate, C., Vudriko, P. and Moumouni, P.F.A. (2016) Molecular survey of canine vector-borne diseases in stray dogs in Thailand. Parasitol. Int., 65(4): 357-361.

17. Ribeiro, C.M., Matos, A.C., Azzolini, T., Bones, E.R., Wasnieski, E.A. and Richini-Pereira, V.B. (2017) Molecular epidemiology of Anaplasma platys, Ehrlichia canis and Babesia vogeli in stray dogs in Paraná, Brazil. Pesq.Vet. Brasil, 37(2): 129-136.

18. Huang, H., Unver, A., Perez, M.J., Orellana, N.G. and Rikihisa, Y. (2005) Prevalence and molecular analysis of Anaplasma platys in dogs in Lara, Venezuela. Braz J. Microbiol., 36(3): 211-216.

19. Pinyoowong, D., Jittapalapong, S., Suksawat, F., Stich, R.W. and Thamchaipenet, A. (2008) Molecular characterization of Thai Ehrlichia canis and Anaplasma platys strains detected in dogs. Infect. Genet. Evol., 8(4): 433-438.

20. Yu, X.J., Zhang, X.F., McBride, J.W., Zhang, Y. and Walker, D.H. (2001) Phylogenetic relationships of Anaplasma marginale and Ehrlichia platys to other Ehrlichia species determined by GroEL amino acid sequences. Int. J. Syst. Evol. Microbiol., 51(3): 1143-1146. 